\title{
Sıfır Değerlikli Alüminyumun Aktive Ettiği Persülfat ile Reactive Yellow 145'in oksidasyonu: Proses şartlarının optimizasyonu
}

\author{
Nevim GENÇ ${ }^{1 *}$, Elif DURNA ${ }^{2}$, Şeyda AYDIN ${ }^{3}$
}

\section{$\ddot{\mathbf{O z}}$}

Sıfır değerlikli alüminyum (ZVAl) çok iyi elektron verici özelliğe sahip olması dolayısı ile atıksudaki pek çok organik ve inorganik kirleticinin yükseltgenme veya indirgenme yolu ile giderilmesinde etkili bir metaldır. ZVAl tarafından verilen elektronlar, ortamda bulunan oksidantlar tarafından alınması sonucu oluşan güçlü radikal türleri ile yükseltgenme tepkimelerine veya bu elektronların kirleticiler tarafından direkt alınarak indirgenme tepkimelerine yol açarak kirleticiyi parçalamaktadır. Bu çalışmada Reactive Yellow 145' in ZVAl ile aktive olmuş persülfat ile oksidasyonu incelenmiştir. Oksidasyon prosesinin işletim koşulları Taguchi Deney Tasarım yaklaşımı ile optimize edilmiştir. Optimum koşullar 60 dakika oksidasyon süresi, $0,8 \mathrm{~g} / \mathrm{L}$ ZVAl dozu, $\mathrm{pH} 10$ ve $15 \mathrm{~g} / \mathrm{L}$ persülfat dozu olarak belirlenmiştir. Optimum koşullarda Reactive Yellow 145 giderim verimi \%76,19 olarak belirlenmiş olup modelin öngördüğü \%77,22 giderim ile uyum içindedir. Oksidasyonu etkileyen her bir parametrenin Reactive Yellow 145 giderim verimine etkisi ANOVA ile açıklanmıştır. Verimi etkileyen en önemli parametrenin \% 80,06 katkı oranı ile pH olduğu belirlenmiştir.

Anahtar Kelimeler: Sıfır değerlikli alüminyum, persülfat, optimizasyon, Reactive Yellow 145

\section{Oxidation of Reactive Yellow 145 by Zero Valent Aluminum Activated Persulfate: Optimization of process conditions}

\begin{abstract}
Zero-valent aluminum ( $\mathrm{ZVAl})$ is an effective metal for removing many organic and inorganic pollutants from wastewater by oxidation or reduction reactions due to its high electron-donating properties. Electrons given by ZVAl, break down the pollutant by causing oxidation reactions with strong radical species formed as a result of taken by oxidants or reduction reactions by being directly taken by pollutants. In this study, the oxidation of Reactive Yellow 145 with ZVAl-activated persulfate was investigated. The operating conditions of the oxidation process were optimized with the Taguchi Experimental Design. Optimum conditions were determined as oxidation time of 60 minutes, ZVAl dose of $0.8 \mathrm{~g} / \mathrm{L}$, $\mathrm{pH}$ of 10 and persulfate dose of $15 \mathrm{~g} / \mathrm{L}$. In optimum conditions, the removal efficiency of Reactive Yellow 145 was determined as $76.19 \%$, which is in compliance with the $77.22 \%$ removal predicted by the model. The effect of each parameter on Reactive Yellow 145 removal efficiency was explained by ANOVA. It was determined that the most important parameter affecting the removal efficiency was $\mathrm{pH}$ with an contribution rate of $80.06 \%$.
\end{abstract}

Keywords: Zero valence aluminum, persulfate, optimization, Reactive Yellow 145.

\footnotetext{
${ }^{1,2,3}$ Kocaeli Üniveresitsi, Çevre Mühendisliği Bölümü, Mühendislik Fakültesi, Kocaeli, Türkiye, ngenc@kocaeli.edu.tr elif.durna@kocaeli.edu.tr sydaydn1994@gmail.com
}

${ }^{1}$ https://orcid.org/0000-0002-6185-1090 ${ }^{2}$ https://orcid.org/0000-0003-4478-2967 ${ }^{3}$ https://orcid.org/0000-0002-6298-8144 


\section{Giriş}

Son yıllarda atık arıtım uygulamalarında nano teknolojinin kullanımı dikkat çekmektedir. Özellikle nano materyallerinin organik ve inorganik kirleticilerin adsorpsiyonunda ve parçalanmasında etkinliği birçok çalışmada kanıtlanmıştır (Ajith ve ark., 2021; Chkirida ve ark., 2021; Rathi ve ark., 2021; Sridevi ve ark., 2021). Nano ve mikro boyutlu sıfır değerlikli alüminyum (ZVAl) kullanılarak kirleticilerin yükseltgenmesi veya indirgenmesi yolu ile giderimi üzerine çalışmalar artmaktadır. Al, düşük maliyetli ve doğada bol miktarda bulunan bir metal olmasının yanı sıra yüksek elektron yoğunluğuna sahip olup kuvvetli indirgeme yeteneğine sahiptir $\left(\mathrm{E}_{0}\left(\mathrm{Al}^{+3} / \mathrm{Al}^{0}\right)\right.$ $=-1,662 \mathrm{~V}$ ) (Xie ve ark., 2020). Bu özelliği atık su arıtımında etkin bir biçimde kullanımını sağlamaktadır.

ZVAl diğer metallerden daha düşük redoks potansiyelinden dolayı elektron transferi için daha büyük termodinamik sürücü güç sağlayabilir (Mahmoud ve ark., 2019). ZVAl 'in nano ve mikro boyutlu olanları karşılaştırıldığında, mikro ölçekli sıfır değerlikli Al (mZVAl)'in kolaylıkla temin edilebilir, daha ucuz ve çevre dostu olduğu görülmüştür (Ren ve ark., 2019). ZVAl'in uygulanması sonucu, çözeltide çözünmüş Al derişimi artar. Ancak sisteme verilen ZVAl dozundan çok düşük seviyelerdedir. 6 saatlik reaksiyon süresi sonunda çözeltide görülen toplam Al iyon derişiminin yüklenen dozun \%o 2'sinden az oranda olduğu belirlenmiştir. Bunun büyük bir kısmının Al(hidro)oksit veya kalıntı ZVAl tozundan oluştuğu ifade edilmektedir (Yang ve ark., 2017). Arıtım süresince $\mathrm{Al}_{2} \mathrm{O}_{3}$ 'ün dissolüsyonu sebebi ile sulu çözeltide alüminyumun önce arttı̆̆ sonrasında ise kısmi flokülasyon ve çökelme ile Al iyonlarının suda azaldığı tespit edilmiştir (Shen ve ark., 2018).

Çok iyi bir elektron vericisi olmasına rağmen mZVAl'ın yıkama ve ön işlem uygulanmaksızın kullanılması durumunda oksit film tabakası varlığından dolayı elektron akışının olmayacağı ifade edilmektedir. Bu özellik mZVAl'in kullanımını sınırlamaktadır (Ren ve ark., 2019). mVZAl dış yüzeyindeki pasif alüminyum oksit film tabakası kirletici giderimini engellemektedir. Arıtım uygulamalarında, Al partikülü üzerindeki pasif oksit tabakası, iç metal Al' in dışını saran su ile etkileşimini önlemektedir (Xie ve ark., 2020). mVZAl'ın reaktivitesini aktive etmek için yüzeydeki oksit filmin giderilmesi gerekmektedir. Bunun için asidik veya alkali yıkama, Al- bazlı bimetaller veya alüminyum alaşımlarının hazırlanması, mekanik öğütme gibi çeşitli metotlar önerilmiştir (Ren ve ark., 2019).

Al'un bulunduğu ortamın pH'ı önemlidir. Asidik çözeltilerde, $\mathrm{H}^{+}$varlığında tabaka parçalanır ve ZVAl korozyona uğrar (Denklem 1 ve 2) (Yang ve ark., 2017).

$$
2 \mathrm{Al}^{0}+2 \mathrm{OH}^{-}+2 \mathrm{H}_{2} \mathrm{O} \rightarrow 2 \mathrm{AlO}_{2}^{-}+3 \mathrm{H}_{2} \uparrow
$$




$$
2 A l^{o}+6 H^{+} \rightarrow 2 A l^{+3}+3 H_{2} \uparrow
$$

$\mathrm{H}_{2} \mathrm{O}$ bu sitemlerde iki reaksiyon meydana getirmektedir. ZVAl partikülleri suyun içinde $\mathrm{Al}_{2} \mathrm{O}_{3}{ }^{\prime}$ in hidrasyon reaksiyonu meydana getirir. Hidrasyon $\mathrm{Al}-\mathrm{O}-\mathrm{Al}$ bağlarının hidroliz yoluyla kırılması $\mathrm{Al}-\mathrm{OH}$ türlerine dönüşümünü ifade etmektedir. Böylece yoğun oksit film kaybolur ve ZVAl'ın elektron salması için uygun hale gelir. Diğer taraftan su ZVAl ile reaksiyon verir ve $\mathrm{H}_{2}$ oluşur, elektronlar tükenmiş olur, kirleticiye aktarılacak elektronların efektif kullanım oranı bu yolla azalmış olur (Yang ve ark., 2017).

Asidik ortamda, oksijen varlığında ZVAl bulunduğu ortamda hikroksil radikal oluşturabilir. Bu oluşumun için optimum pH 2 olarak ifade edilmektedir. Arıtım uygulamalarında sistemde kendiliğinden oluşan $\mathrm{H}_{2} \mathrm{O}_{2}$ yeterli gelmemesi durumunda dışarıdan ilave edilmektedir (Denklem 4 ve 5) (Mahmoud ve ark., 2019).

$$
\begin{aligned}
& \mathrm{Al}^{0}+3 \mathrm{O}_{2}+6 \mathrm{H}^{+} \rightarrow 2 \mathrm{Al}^{+3}+3 \mathrm{H}_{2} \mathrm{O}_{2} \\
& \mathrm{Al}^{0}+3 \mathrm{H}_{2} \mathrm{O}_{2} \rightarrow \mathrm{Al}^{+3}+3 \mathrm{OH}^{-}+3 \mathrm{HO}^{\circ}
\end{aligned}
$$

Sıfır değerlikli metalin uygulandığı ileri oksidasyon proseslerinde, katalizör ilavesi ile arıtma verimi geliştirmiştir.

ZVAl, persülfatı (PS) aktive edecek mükemmel heterojen bir elektron vericidir. Bu özelliğin kullanıldığı ZVAl / PS sistemlerinde arıtım çalışmaları yapılmıştır. Teorik olarak 1 mol ZVAl , 3 mol elektron salar, direkt olarak elektron transfer yolu ile PS aktivasyonunu sağlar (Ren ve ark., 2019).

ZVAl'in verdiği elektronları alan PS, sülfat radikali $\left(\mathrm{SO}_{4}{ }^{-}\right)$oluşturur. $\mathrm{SO}_{4^{-}}{ }^{-}$ile $\mathrm{H}_{2} \mathrm{O} / \mathrm{OH}^{-}$ arasındaki reaksiyon $\mathrm{OH} \cdot$ radikali oluşturabilir (Denklem 8 ve 9) (Ren ve ark., 2019).

$$
\begin{aligned}
& \mathrm{SO}_{4}^{--}+\mathrm{OH}^{-} \rightarrow \mathrm{SO}_{4}^{-2}+\mathrm{OH}^{\cdot} \\
& \mathrm{SO}_{4}^{--}+\mathrm{H}_{2} \mathrm{O} \rightarrow \mathrm{SO}_{4}^{-2}+\mathrm{OH}^{\cdot}+\mathrm{H}^{+}
\end{aligned}
$$

Bunun yanı sıra denklem 10'da görüldüğü gibi $\mathrm{H}_{2} \mathrm{O}_{2}$ ve PS gibi oksidantların ilavesi hidroksil radikali ve $\mathrm{SO}_{4}{ }^{-}$oluşumunu sağlamaktadır (Khatri ve ark., 2018).

$$
2 \mathrm{Al}^{0}+\mathrm{S}_{2} \mathrm{O}_{8}^{-2}+6 \mathrm{H}^{+}+1,5 \mathrm{O}_{2} \rightarrow 2 \mathrm{Al}^{+3}+2 \mathrm{SO}_{4}^{--}+3 \mathrm{H}_{2} \mathrm{O}
$$


Yüksek persülfat derişimleri ise, sülfat radikallerinin, sülfat iyonuna dönüşümünü sağlar ve yükseltgeme verimi düşer (Denklem 11 ve 12) (Khatri ve ark., 2018).

$$
\begin{aligned}
& \mathrm{SO}_{4}^{--}+\mathrm{SO}_{4}^{--} \rightarrow 2 \mathrm{SO}_{4}^{-2} \\
& \mathrm{SO}_{4}^{--}+\mathrm{S}_{2} \mathrm{O}_{8}^{-2} \rightarrow \mathrm{S}_{2} \mathrm{O}_{8}^{-}+\mathrm{SO}_{4}^{-2}
\end{aligned}
$$

ZVAl, sulu çözeltilerde elektron kaynağıdır, kuvvetli indirgeyici kapasiteye sahip olmasından dolayı çevre koşulları altında kolaylıkla oksitlenebilir. Çok kuvvetli indirgeme performansı göstermesi sebebi ile arıtım uygulamalarında reaktif indirgeyici ajan olarak kullanılmıştır [6]. İndirgeme prosesinde kirleticiler elektron alıcısı olarak iş görür. ZVAl, efektif elektron vericisi olmasına rağmen, hızlı alüminyum oksit ve hidroksit oluşumu, reaktif ajan olarak uygulamasını sınırlar. ZVAl, ZVAl oksidi ve hidroksidi amfoteriktir. Su arıtımında ZVAl yükseltgeme ve indirgeme reaksiyonları ile kirleticiyi parçalayabilir. Yükseltgeme sistemleri $\mathrm{ZVAl} / \mathrm{O}_{2}$ veya oksidantlar $/ \mathrm{H}^{+}$kombinasyonlarını kapsar. Bunun gerçekleşebilmesi için kuvvetli asidik şartlar gereklidir. Nötrale yakın şartlarda ZVAl'ın oksit film tabakası kırılmadığı için giderim verimliliği düşük olmaktadır. Alkali koşullarda $\mathrm{O}_{2}$ 'den $\mathrm{H}_{2} \mathrm{O}_{2}$ üretmek güçtür, çünkü elektronlar $\mathrm{H}_{2} \mathrm{O}$ ve $\mathrm{H}_{2}$ üretmek için transfer olur. $\mathrm{O}_{2}, \mathrm{H}_{2} \mathrm{O}$ ve kirleticiler gibi bazı maddeler arasında elektronlar için rekabet vardır. Elektronu en iyi alan $\mathrm{O}_{2}$ 'dır. $\mathrm{Bu}$ yüzden kirleticinin indirgenmesinin istendiği ortamlarda çözünmüş oksijen giderilmelidir. Bunun yanı sıra oksit film tabakası $\mathrm{Al} / \mathrm{H}_{2} \mathrm{O}$ reaksiyonu ile gevşeyebileceği de dikkate alınmalıdır (Yang ve ark., 2017).

Stabil oksijen molekülleri belirli şartlar altında reaktif oksijen türleri üretmek üzere $\left(\mathrm{O}_{2}{ }^{-}, \mathrm{H}_{2} \mathrm{O}_{2}\right.$ ve $\mathrm{OH} \cdot$ ) aktive olabilir. $\mathrm{Bu}$ türler organik kirleticileri etkili olarak parçalayabilir. Çevresel uygulamalar için oksijenin aktivasyonu önemlidir. ZVAl ile oksijenin aktivasyonu dikkat çeken bir yöntem olmuştur. ZVAl 'in yüksek bir negatif redox potansiyeline sahip olması onun daha hızlı elektron transfer hızı ve daha yüksek $\mathrm{O}_{2}$ aktivasyon verimliliğine sahip olduğunu gösterir (sıfır değerlikli demir $(\mathrm{ZVI})$ için $\mathrm{E}^{0}\left(\mathrm{Fe}^{+2} / \mathrm{Fe}\right)=-0,44 \mathrm{~V}, \mathrm{ZVAl}$ için $\left.\mathrm{E}^{0}\left(\mathrm{Al}^{+3} / \mathrm{Al}\right)=-1,67 \mathrm{~V}\right)$. Korozyon potansiyeli, indirgeme kapasitesi indeksi olarak iş görür. ZVAl için korozyon potansiyeli $-0,66 \mathrm{~V}$, ZVI'in -0,58 V dur. Bu ise $\mathrm{O}_{2}$ 'i aktive etmek için ZVAl'ün, ZVI'dan daha kolay elektronlar vereceği anlamina gelmektedir (Shen ve ark., 2018).

ZVAl ile organik ve inorganik bazı kirleticilerin (Bisfenol-A (Dogan ve ark., 2016), 4klorofenolün (Bokare ve Choi, 2009), trikloroetilen (Ren ve ark., 2019), metil oranj ve metilen mavisi (Xie ve ark., 2020), Cr(VI) (Ren ve ark., 2020), atrazin (Shen ve ark., 2018), hekzabromosiklododekan (Jiang ve ark., 2020) gideriminde oldukça başarılı sonuçlar elde edilmiştir. 
ZVAl'in pasif tabakasının parçalanması ve elektronların elektron alıcısına akış mekanizması Şekil 1'de gösterilmektedir.

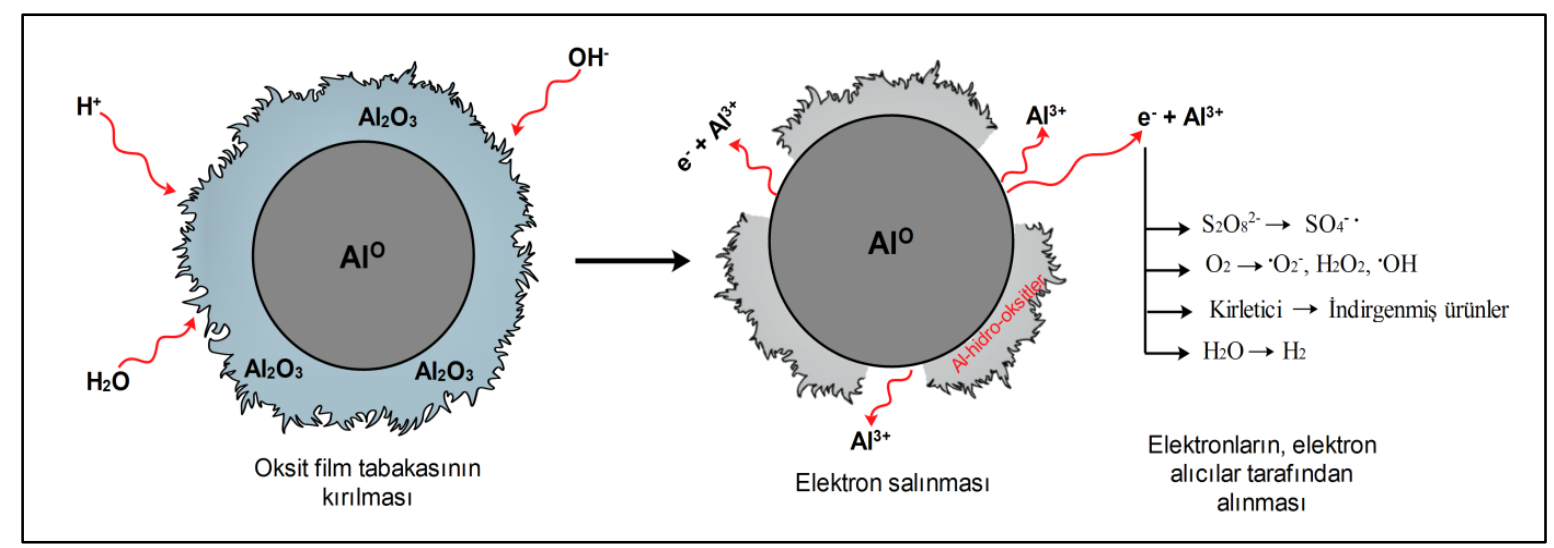

Şekil 1. ZVAl'in pasif tabakasının parçalanması ve elektronların elektron alıcıya akışı.

ZVAl'ın su ve atık su arıtmasındaki uygulamaları tek sistem, bimetal sistem ve ileri oksidasyon süreçleri olmak üzere üç bölümde ele alınabilir. ZVAl, güçlü bir indirgeyici ajan ve adsorbandır. Ayrıca, koşulları değiştirerek ve bimetalik sistemler kullanarak diğer ZVM (sıfır değerlikli metal) ile birlikte ZVAl'ın performansı geliştirilebilir. ZVAl, bimetal sistemde (Fe / Al, Pd / $\mathrm{Al}, \mathrm{Cu} / \mathrm{Al}$ ) çeşitli kombinasyonlarda, sulu ortamdan çeşitli kirletici maddeleri uzaklaştırabilir Ayrıca, ZVAl'in su ortamında hidroksil ve sülfat radikalleri üretebildiğini ve biyolojik olarak parçalanamayan kirleticilerin giderilmesini geliştirdiği ispatlanmıştır (Nidheesh ve ark., 2018). Kirleticilerin ZVAl ile parçalanmasında önemli faktörler aşağıdaki şekilde sıralanabilir;

ZVAl dozu: ZVAl dozunun artışı ile birlikte reaktif yüzey alanı artar, bu durum daha çok elektron salınımına neden olacağından kirleticinin parçalanması artar (Jiang ve ark., 2020). ZVA1 dozu, parçalanma reaksiyonları için elektron salabilecek aktif bölgelerin varlığını arttırması yanı sıra ayrıca kirleticinin adsorpsiyonu içinde alan sağlaması bakımından önemlidir (Mahmoud ve ark., 2019). ZVAl dozunun artışı ile kirletici gideriminin artması, $\mathrm{Al}^{0}$ korozyonu ile oluşan $\mathrm{H}_{2} \mathrm{O}_{2}$ 'nin artması ve metalin toplam yüzey alanının artması ile açıklanmıştır (Zhang ve ark., 2012).

Çözünmüş oksijenin etkisi: ZVAl (Denklem 4) ve (Denklem 5)'te gösterildiği üzere hidroksil radikalleri üretebilir. Asidik ve çözünmüş oksijen bulunan ortamda $\mathrm{H}_{2} \mathrm{O}_{2}$ oluşur ve daha ileri 
reaksiyon ile hidroksil radikalleri meydana gelir. Hidroksil radikali oluşumu için ideal pH 2 olarak ifade edilmektedir (Khatri ve ark., 2018). ZVAl ile kirletici giderim proseslerinde ZVAl'den salınan elektronlar oksitleyici türlere $\left(\mathrm{O}_{2}, \mathrm{H}_{2} \mathrm{O}\right.$ veya kirletici) geçer. Oksijen elektron alıcısı olarak $\mathrm{H}_{2} \mathrm{O}$ ve kriletici ile rekabet eder. Elektron alıcısı olarak proseste kullanılır (Ren ve ark., 2018; Yang ve ark., 2017). Oksijenin varlığında ZVAl bazlı ileri oksidasyon proseslerinde yüksek dereceden $\mathrm{H}_{2} \mathrm{O}_{2}$ üretimi ve ardından hidroksil radikali üretimi gözlenmiştir. Oksijenin bulunmadığı ortamda ise hidroksil radikalleri ZVAl ile dışarıdan ilave edilen $\mathrm{H}_{2} \mathrm{O}_{2}$ arasındaki reaksiyonla üretilir (Nidheesh ve ark., 2018). Oksijenin varlığ 1 oksit filmin oluşmasına sebep olabilir ve elektronların alınmasında rekabet yaratır. Metalik alüminyum çözünmüş oksijen ile temasta olduğu zaman oksit film oluşur, dolayısı ile elektron salınımı etkilenir (Jiang ve ark., 2020).

Sıcaklığın Etkisi: Sıcaklık, ZVAl'in yer aldığı reaksiyonlar üzerinde önemli bir etkiye sahiptir. Artan sıcaklıklar ile reaksiyon hızının belirgin bir şekilde arttığı bilinmektedir. Hem nano hem de mikro boyutlu ZVAl ortam basıncı altında hafif sıcaklıkta su ile reaksiyona girerek hidrojen üretebilir. Nano ZVAl tozu $20{ }^{\circ} \mathrm{C}$ 'de suyla tamamen reaksiyona girebilirken mikro ZVAl tozlarının çoğu $>40$ ${ }^{\circ} \mathrm{C}$ sicaklıkta su ile reaksiyona girebilir, bu da küçük boyutlu Al tozunun herhangi bir aktivasyon olmaksızın suyla reaksiyona girebileceğini ve hidrojen üretebileceğini göstermektedir (Gai ve ark., 2012). ZVAl kullanıldığgı sistemde sıcaklığın bromat giderimi üzerine etkisi incelendiğinde, sıcaklığın artması ile bromat gideriminin pozitif yönde arttığı belirlenmiştir (Lin ve Lin, 2016).

Anyonların etkisi: $\mathrm{SO}_{4}{ }^{-2}, \mathrm{Cl}^{-}, \mathrm{NO}_{3}{ }^{-}, \mathrm{PO}_{4}{ }^{3-}$ gibi anyonlar $\mathrm{ZVAl}^{\prime}$ 'n yüzeyini kaplar ve krileticilerin ZVAl yüzeyi ile temasını azaltarak verimi düşürür (Lin ve ark., 2017). $\mathrm{SO}_{4}^{-2}, \mathrm{Cl}^{-}$, iyonları sularda bol miktarda bulunan iyonlar olup, bunların varlığı ZVAl ile kirleticinin parçalanma verimini düşürmektedir. $\mathrm{SO}_{4}^{-2}$ in etkisinin $\mathrm{Cl}^{-}$den daha kuvvetli olduğu belirlenmiştir. $\mathrm{Bu}$ ise $\mathrm{SO}_{4}^{-}$ 2'nin çift yüke sahip olması ve böylece alüminyum yüzeyi için kuvvetli adsorptif ilgiye sahip olması ile açıklanmıştır. Bunun yanı sıra $\mathrm{Cl}^{-}$in ZVAl üzerinde oluşturduğu korozyonun daha önemli olduğu vurgulanmaktadır. $\mathrm{Cl}^{-}$, Al-(hidro) oksiti belirli bir seviyeye kadar parçalayabilir. Ayrıca iyon derişimi arttıkça kirleticinin parçalanmasının azaldığı belirlenmiştir. Bu durum ise, kirletici ve iyonların, ZVAl'in reaktif yerleri için rekabet etmelerinden kaynaklandığı şeklinde açıklanmıştır (Jiang ve ark., 2020) (Li ve ark., 2021).

pH'in etkisi: ZVAl'in içinde bulunduğu sulu çözeltinin pH'1, ZVAl'in korozyonunun etkileyen çok önemli parametredir. Oksit film için korozyonu $\mathrm{pH}<4,00$ veya $\mathrm{pH}>8,60$ 'da hızlıca meydana gelir. Asidik koşullar altında pasif oksit film tabakasının korozyonu, alkali koşullardan daha azdır (Denklem 13 ve 14) (Jiang ve ark., 2020).

$$
\mathrm{Al}_{2} \mathrm{O}_{3}+6 \mathrm{H}^{+} \rightarrow \mathrm{ZAl}^{+3}+3 \mathrm{H}_{2} \mathrm{O}
$$




$$
\mathrm{Al}_{2} \mathrm{O}_{3}+\mathrm{H}_{2} \mathrm{O}+2 \mathrm{OH}^{-} \rightarrow 2 \mathrm{Al}(\mathrm{OH})_{4}^{-}
$$

Literatürde ZVAl içeren sistemlerde çeşitli oksidantların kullanımı ile kirleticinin oksidasyon ile giderimi ya da oksijen kullanılmayan sistemlerde indirgenme reaksiyonları üzerinden kirletici giderimi üzerine çalışmalar mevcuttur. Bu sistemlerde proses şartlarının etkilerinin tek tek ele alındığı belirlenmiştir. Proses şartlarının optimizasyonu için geniş çaplı çalışma olmadığı görülmektedir.

$\mathrm{Bu}$ çalışmada ZVAl elektron verici, persülfat elektron alıcı ve oksitleyici ajan olarak kullanılarak Reactive Yellow 145 boyar maddesinin oksidasyonu incelenmiştir. Oksidasyon prosesini etkileyen şartlar birlikte ele alınarak, en yüksek boya giderim verimi sağlayacak biçimde optimize edilmiştir. Optimizasyonda L9 Taguchi Deney Tasarım Modeli kullanılmıştır. Oksidasyonda etkili parametrelerin bireysel önem dereceleri varyans analizi (ANOVA) ile belirlenmiştir.

\section{Materyal ve Metot}

Materyal: Bu çalışmada Reactive Yellow 145 reaktif boyar maddesi kullanılmıştır. Azo boyalar sınıfında yer alan boyar madde, boyama işlemi yapan tekstil fabrikasından temin edilmiş olup saflaştırmaksızın kullanılmıştır. Merck'den temin edilen \%2 yağ içeriğine sahip stabilize edilmiş ince toz formunda ZVAl (26,98 g/mol) aktivatör olarak kullanılmıştır. pH ayarlamak için kullanılan $\mathrm{HCl}$, $\mathrm{NaOH}$ ve oksitleyici ajan olarak kullanılan sodyum persülfat Merck'den temin edilmiştir.

Deneysel Çalışma: Boyar maddenin oksidasyonu üzerine yapılan çalışmada ZVAl, persülfatı aktive etmek için kullanılmıştır. Deneysel çalışma L9 Taguchi Deneysel Tasarım deseninde verilen şartlar uygulanarak yürütülmüş̧ür. Kesikli sistemde $50 \mathrm{ml}$ çalışma hacmine sahip kapaklı tüplerde yürütülen çalışmada ZVAl partiküllerinin çözelti ile tam karışımının sağlanması için oda sıcaklığındaki su banyosunda yatay konumlandırılarak karıştırılmıştır. Oksidasyon sonunda alınan numunelerde boyar madde analizi yapılmıştır. Boyar maddesinin analizi Hach Lange DR-6000 UVVIS spektrofotometre kullanılarak spektrofotometrik olarak yapılmıştır. Boya çözeltisinin maksimum absorbans veren dalga boyunda $(419 \mathrm{~nm})$, çözeltilerin absorbansı belirlenmiştir. Standart boya çözeltilerin konsantrasyonuna karşı absorbans değerlerinin ilişkisini ifade eden kalibrasyon eğrisi (Absorbans $=0,067 x$ Boya konsantrasyonu $\left.(\mathrm{mg} / \mathrm{L})-0,007, \mathrm{R}^{2}=0,998\right)$ yardımı ile boyar maddenin konsantrasyonu belirlenmiştir.

\subsection{Taguchi Deneysel Tasarım Metodu}

Taguchi Deney Tasarımı ortogonal deney düzeni kullanan bir optimizasyon tekniğidir. Taguchi Deney Tasarımının en büyük avantajı yanıta etki eden pek çok faktör eş zamanlı olarak daha az sayıda 
deney ile optimize edebilmesidir (Kavcı ve ark., 2021). Deneysel sonuçlardan elde edilen veriler Sinyal/Gürültü (S/N) oranına dönüştürülür. S / N oranı (istenen kısım / istenmeyen kısım)'^1 temsil eder.

$\mathrm{Bu}$ çalışmada boyar maddenin oksidasyon veriminin en yüksek seviyelerde sağlayacak oksidasyon şartların belirlenmesi amaçlanmıştır. Taguchi Deney Tasarımı'nda karakteristik tipine bağlı olarak daha düşük daha iyi, daha büyük daha iyi ve nominal daha iyi olmak üzere mevcut üç $S$ / N oranı vardır. Her bir karakteristik için S / N oranları hesaplanabilir (Arıcı ve Keleştemur, 2018). Bu çalışmada Taguchi Deneysel Tasarım Metodunda “daha büyük daha iyi” durumu ifade eden S/N dikkate alınmıştır. Bu durum için S/N değeri denklem 15'teki eşitlik ile gösterilir (Ross 1996).

$$
\frac{S}{N}=-\log 10\left(\frac{1}{n} \sum_{i=1}^{n} \frac{1}{y_{i}^{2}}\right)
$$

$\mathrm{y}_{\mathrm{i}}$, kontrol faktörü seviyelerinin belirli bir kombinasyonu için i’nci deneyde gözlemlenen performans karakteristiği ve n, tekrar sayısıdır.

Taguchi L9 deney tasarım deseni oluşturulabilmesi için oksidasyon prosesinde etkili 3 seviyeli 4 faktör belirlenmiştir. Faktör ve seviyelerinin belirlenmesi aşamasında ön denemeler ve literatür verileri dikkate alınmıştır (Ren ve ark., 2018; Yang ve ark., 2017). Parametre seviyeleri, deney deseninde düşük, orta ve yüksek boya giderim verimi elde edilecek biçimde seçilmesine özen gösterilmiştir. Oksidasyon prosesinde etkili faktör olarak ZVAl dozu, Persülfat dozu, çözeltinin pH ve oksidasyon süresi seçilmiştir. Her bir faktörün seviyesi Tablo 1 de verilmiştir. Oksidasyon prosesinde cevap parametresi olarak boyar madde giderim verimi (\%) belirlenmiştir. Taguchi Deneysel Tasarımı Design Expert 10 yazılımı ile çözümlenmiştir.

Tablo 1. Deneysel tasarım için belirlenen faktörler ve seviyeleri.

\begin{tabular}{llll}
\hline Faktör/Seviye & Seviye 1 & Seviye 2 & Seviye 3 \\
\hline Oksidasyon süresi (dakika) & 40 & 60 & 80 \\
\hline $\mathrm{pH}$ & 3 & Orijinal $(6,2)$ & 10 \\
\hline ZVAl dozu (g/L) & 0,4 & 0,8 & 1,6 \\
\hline PS (g anion/L) & 5 & 10 & 15 \\
\hline
\end{tabular}

Çalışmada ayrıca varyans analizi (ANOVA) yapılmıştır. Varyans analizi bağımsız değişkenlerin ve bunların etkileşimlerinin yanıtlar üzerindeki etkisini açıklar. ANOVA ile deneysel set içerisindeki tüm faktörlerin toplam varyansı ile her faktörün varyansı karşılaştırılarak faktörlerin birbirlerine göre etkisi belirlenir (Sohrabi ve ark., 2017). Fisher testi (F değeri) ve olasılık (p değeri) faktörlerin istatistiksel önemini ifade etmek için kullanılır. ANOVA analizinde 0,05 'ten küçük P 
değeri ve büyük F değeri o parametrenin performans karakteristiği üzerinde daha büyük etkisi olduğunu ifade etmektedir (Dhawane ve ark., 2016).

\section{Bulgular ve Tartışma}

Taguchi L9 ortogonal deney tasarımı ve her bir deneyde yanıt parametresi olarak değerlendirilen boya giderim veriminin aldığı değerler Tablo 2'de verilmiştir. Oksidasyon proses şartları, en yüksek boya giderim verimi elde edilecek biçimde optimize edilmiştir.

Tablo 2. Deney tasarımı ve yanıt parametresi

\begin{tabular}{cccccc}
\hline $\begin{array}{c}\text { Deney } \\
\text { No }\end{array}$ & $\begin{array}{c}\text { Oksidasyon } \\
\text { süresi(dakika) }\end{array}$ & $\mathrm{pH}$ & $\begin{array}{c}\mathrm{PS} \\
(\mathrm{g} / \mathrm{L})\end{array}$ & $\begin{array}{c}\text { ZVAl dozu } \\
(\mathrm{g} / \mathrm{L})\end{array}$ & Verim (\%) \\
\hline 1 & 40 & 3 & 5 & 0,4 & 50,10 \\
\hline 2 & 40 & 6,2 & 10 & 0,8 & 18,73 \\
\hline 3 & 40 & 10 & 15 & 1,6 & 70,48 \\
\hline 4 & 80 & 3 & 15 & 0,8 & 72,35 \\
\hline 5 & 60 & 10 & 5 & 0,8 & 73,48 \\
\hline 6 & 80 & 6,2 & 5 & 1,6 & 18,73 \\
\hline 7 & 60 & 6,2 & 15 & 0,4 & 14,60 \\
\hline 8 & 80 & 10 & 10 & 0,4 & 67,85 \\
\hline 9 & 60 & 3 & 10 & 1,6 & 74,23 \\
\hline
\end{tabular}

Oksidasyon prosesini etkileyen her bir değişkenin yanıt üzerindeki etkisi ANOVA ile belirlenmiştir (Tablo 3). Parametrelerden PS miktarının kareler toplamı en düşük değeri aldığı için hataya dahil edilmiştir. Modele ait P değeri $0,0345<0,05$ olduğundan elde edilen modelin anlamlı olduğu görülmüştür. Modelin $\mathrm{R}^{2}$ değeri 0,9884 olarak elde edilmiştir. Tahmin edilen $\mathrm{R}^{2}(0,7647)$ ile düzeltilmiş $\mathrm{R}^{2}(0,9535)$ arasındaki fark 0,2 'den düşük olduğu için uyum içindedir. Modelde $\mathrm{S} / \mathrm{N}$ oranın bir göstergesi olarak hassasiyet oranı (adeq precision) kullanılır. Hassasiyet oranı sinyalgürültü oranını ölçer ve 4'ten büyük bir oran arzu edilir. Bu çalışmada hassasiyet oranı 12,7367 olarak bulunduğundan modelin, tasarım için kullanılabilir olduğu söylenebilir (Gupta ve Mondal, 2019).

ANOVA tablosunda $\mathrm{F}$ ve $\mathrm{P}$ değerlerine bakıldığında oksidasyon prosesinde boya giderim verimini etkileyen en önemli parametrenin yüksek bir etkiyle $\mathrm{pH}$ parametresi olduğu, sonrasında ZVAl dozu olduğu görülmektedir. Oksidasyon prosesine etkisinin en düşük olduğu parametre PS dozu olduğundan modelde hataya dahil edilmiştir. 
Tablo 3. Deney tasarımı ve yanıt parametresi

\begin{tabular}{lccccc}
\hline & $\begin{array}{c}\text { Kareler } \\
\text { Toplamı }\end{array}$ & $\begin{array}{c}\text { Serbestlik } \\
\text { Derecesi }\end{array}$ & $\begin{array}{c}\text { Ortalama } \\
\text { Kareler } \\
\text { Toplam1 }\end{array}$ & $\begin{array}{c}\mathrm{F} \\
\text { Değeri }\end{array}$ & $\begin{array}{c}\mathrm{P} \\
\text { Değeri }\end{array}$ \\
\hline Model & 5508,13 & 6 & 918,02 & 28,35 & 0,0345 \\
\hline $\begin{array}{l}\text { A-Oksidasyon } \\
\text { süresi }\end{array}$ & 102,91 & 2 & 51,45 & 1,59 & 0,3863 \\
\hline B-pH & 5185,27 & 2 & 2592,64 & 80,06 & 0,0123 \\
\hline D-ZVAl dozu & 219,95 & 2 & 109,97 & 3,40 & 0,2275 \\
\hline Hata & 64,77 & 2 & 32,38 & & \\
\hline Toplam & 5572,89 & 8 & & & \\
\hline
\end{tabular}

Şekil 2'de gösterildiği üzere oksidasyon prosesinde elde edilen gerçek değerler ile modelin tahmin değerleri arasında uyumlu bir ilişkinin olduğu görülmektedir.

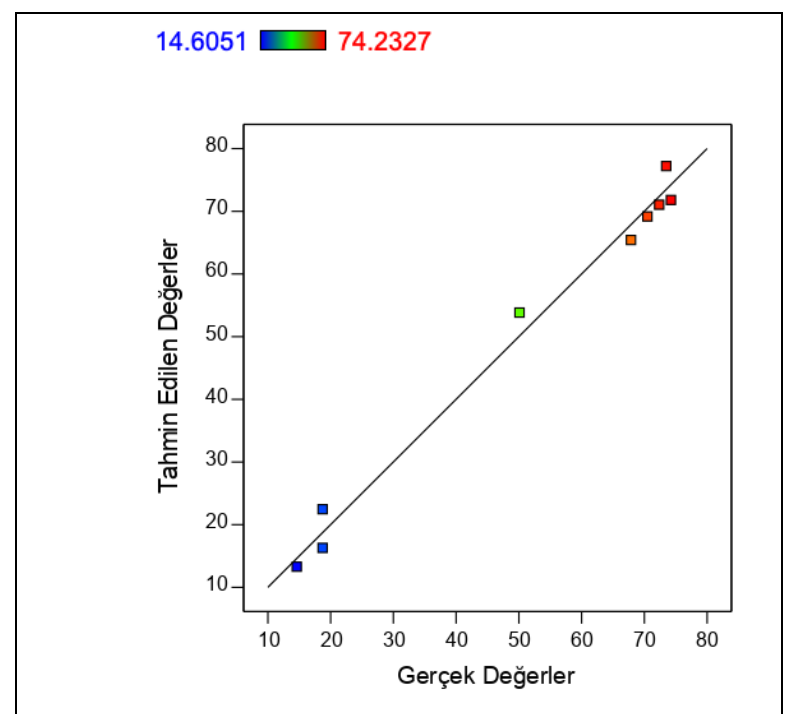

Şekil 2. Reactive Yellow 145 giderim veriminin gerçek değerleri ile model tahmin değerleri arasındaki ilişki.

Proses optimizasyon sonuçları ve doğrulama deneyi ile elde edilen sonuçlar Tablo 4'de verilmiştir. Belirlenmiş optimum şartlar deney deseninde yer almamaktadır. Bu şartlar altında yapılan deney neticesinde elde edilen gerçek renk giderimi \% 76,19 olarak belirlenmiştir. Bu değer modelin öngördüğü ortalama \%77,22 renk giderim verimi ile \%95 güven aralığında verdiği maksimum ve minimum giderim verimleri ile uyumludur.

Tablo 4. Optimum koşullar, öngörülen ve gerçek renk giderimi

\begin{tabular}{lll}
\hline Optimum şartlar & $\begin{array}{l}\text { Öngörülen Renk Giderimi } \\
(\%)\end{array}$ & $\begin{array}{l}\text { Gerçek Renk Giderimi } \\
(\%)\end{array}$ \\
\hline Oksidasyon süresi: 60 dakika & $\begin{array}{l}\% 95 \text { güven aralığında } \\
\% 76,19\end{array}$ \\
ZVAl dozu: $0,8 \mathrm{~g} / \mathrm{L}$ & $\begin{array}{l}\text { Minimum \% 54,50 } \\
\text { pH: } 10\end{array}$ & Maksimum \%97,69 \\
PS dozu:15 g/L & & \\
\hline
\end{tabular}




\subsection{Proses Değişkenlerinin Renk Giderim Verimine Etkisi}

Şekil 3'te boya maddesi gideriminde etkili parametrelerin etkileşimleri verilmiştir. Oksidasyon prosesinde en etkili parametrenin pH olduğu belirlenmiştir. Şekil 3a'da PS 5 g/L, ZVAl 0,4 g/L sabit şartlar altında farklı pH'lara sahip boya çözeltilerinin oksidasyon durumu incelendiğinde, asidik ve bazik ortam koşullarında boya giderim verimlerinin orijinal $\mathrm{pH}$ durumuna göre çok yüksek olduğu gözlenmiştir. Renk giderim verimi orijinal pH'da 60 dakika oksidasyon süresince yaklaşık \%10 seviyelerinde iken pH 3 ve 10'da yaklaşık olarak \%60 seviyelerine ulaşmıştır. Renk giderim verimi, 60 dakika oksidasyon süresince maksimum seviyeye ulaşmıştır, ancak sürenin 120 dakikaya uzatılması ile verimde önemsiz dereceden düşüşler gözlemlenmiştir. Bu durum uzun oksidasyon süresi ile pasif tabakanın kısmen yeniden oluşma olasılığını ifade etmektedir. PS varlığında ZVAl'ın yüzey korozyon mekanizması incelendiğinde, PS'nin oksitleyici etkisi ile korozyonun hızlandığ fakat aynı zamanda korozyon ürünleri olan Al-(hidro)oksit'in çökelmesi sonucu sekonder pasif tabakanın oluştuğu ve bu durumun ZVAl reaktivitesini azalttığı ifade edilmiştir (Ren ve ark., 2019).

Şekil 3b' de pH 3, PS 5 g/L sabit durumda, farklı oksidasyon sürelerinde ZVAl dozuna karşı boya giderim veriminin değişimi verilmiştir. ZVAl dozu 0,4 g/L'den 0,8 g/L'ye artması ile renk giderim verimi en yüksek seviyeye ulaşmıştır. 1,6 g/L dozunda ise verimde önemsiz ölçüde azalma gözlenmiştir. Bu eğilim tüm oksidasyon sürelerinde belirlenmiş olup, 60 dakika oksidasyon süresinde verim maksimum seviyelerde kalmıştır. Şekil 3c'de PS 5 g/L, ZVAl 0,4 g/L sabit şatlarda, pH değişimine karşı farklı oksidasyon sürelerindeki renk giderim verimi gösterilmiştir. Şekilden görüldüğü üzere, asidik ve bazik koşullarda, 60 dakika oksidasyon süresinde verim yüksek seviyelerde kalmıştır. 
a)

X1 = A: Oksidasyon süresi $\mathrm{X} 2$ = B: $\mathrm{pH}$

Actual Factors

C: $\mathrm{PS}=5$

$\mathrm{D}: \mathrm{ZVA}=0,4$

$\square \mathrm{B} 13$

$\triangle$ B2 orjinal

• B3 10

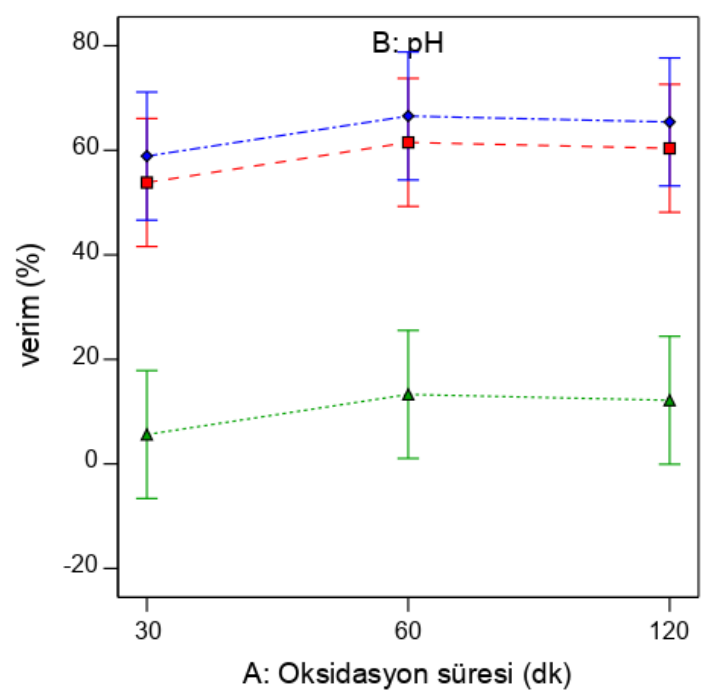

b)

X1 = D: ZVAl

$\mathrm{X} 2$ = A: Oksidasyon süresi

Actual Factors

$\mathrm{B}: \mathrm{pH}=3$

C: $P S=5$

$\square \mathrm{A} 130$

$\triangle \mathrm{A} 260$

- A3 120

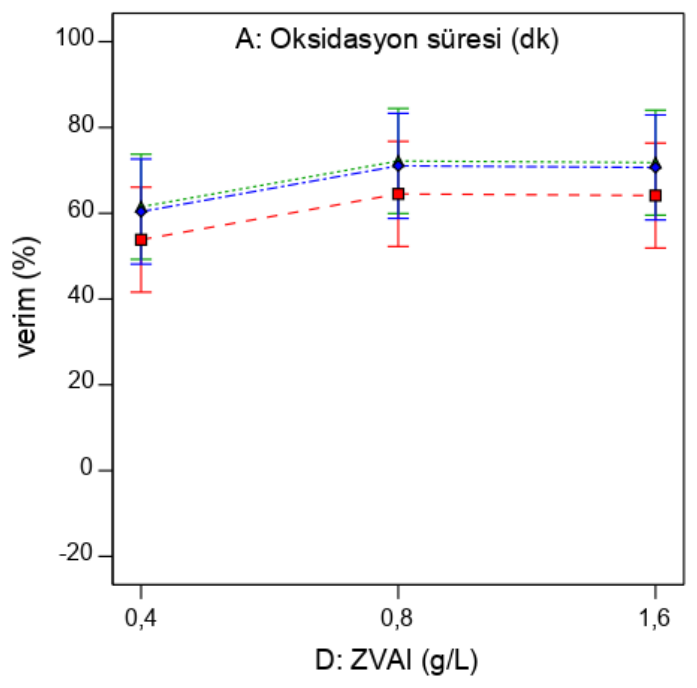

c)

$\mathrm{X} 1=\mathrm{B}: \mathrm{pH}$

X2 = A: Oksidasyon süresi

Actual Factors

C: $P S=5$

D: ZVA $=0,4$

$\square \mathrm{A} 130$

$\triangle \mathrm{A} 260$

- A3 120

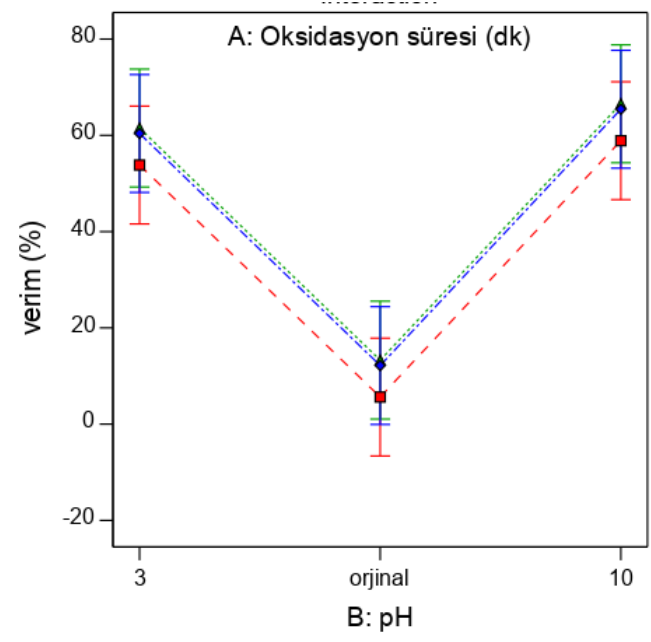

Şekil 3. Oksidasyon prosesini etkileyen parametreler arasındaki etkileşim 


\subsection{UV-Görünür Absorpsiyon Spektrumundaki Değişim}

Ham boya çözeltisinin ve optimum proses şartlarında okside olmuş boya çözeltisinin UVgörünür bölge absorpsiyon spektrumu Şekil 4’te verilmiştir. $419 \mathrm{~nm}$ ve $294 \mathrm{~nm}$ dalga boyundaki absorpsiyon piklerinin sırası ile $-\mathrm{N}=\mathrm{N}$ - bağları ve aromatik halkaların varlığını gösterdiği tahmin edilmektedir (Xie ve ark., 2020; Yang ve ark., 2017). Oksidasyon sonucunda 419 nm'deki absorpsiyon piki azalmış \%70 dolaylarında düşmüştür, bu kromoforik grubun, oksidasyon süresince kırıldığını göstermektedir. UV bölgesindeki adsorpsiyon pikinin dalga boyunda değişimler gözlenmiştir. $\mathrm{Bu}$ oksidasyon sonucunda farklı dalga boylarında absorpsiyon piki veren aromatik bileşiklerin oluşma olasılığını göstermektedir. UV bölgesindeki piklerin yer değişimi, aromatik halkalardaki elektron absorpsiyon geçişlerindeki değişimlerden kaynaklandığ 1 ifade edilmektedir (Xie ve ark., 2020).

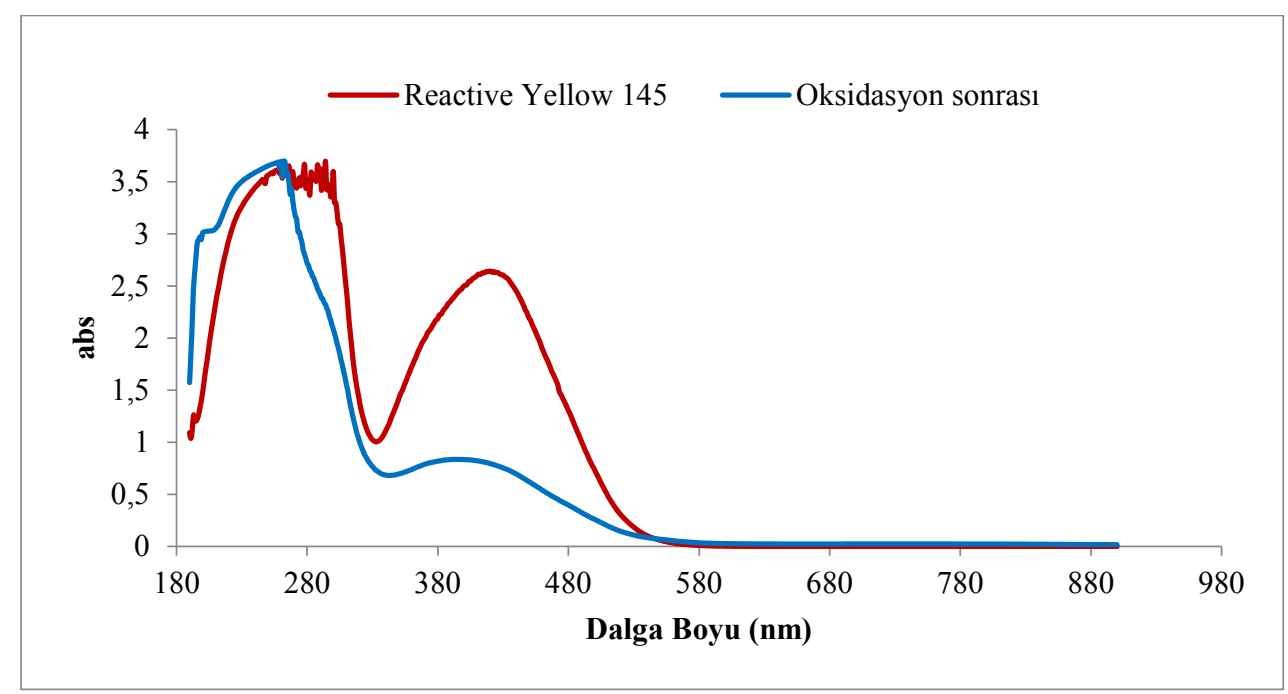

Şekil 4. Ham ve okside olmuş Reactive Yellow 145 'in UV-Görünür bölge spektrumu

\section{Sonuçlar ve Öneriler}

$\mathrm{Bu}$ çalışmada tekstil sektöründe kullanılan Reactive Yellow 145'in ZVAl ile aktive edilen persülfatın oluşturduğu sülfat radikali ile oksidasyonu incelenmiştir. Oksidasyon proses şartları Taguchi Deneysel Tasarım yaklaşımı ile optimize edilmiştir. Çalışmada elde edilen sonuçlar aşağıda sunulmuştur:

-60 dakika oksidasyon süresi, 0,8 g/L ZVAl dozu, $\mathrm{pH} 10$ ve $15 \mathrm{~g} / \mathrm{L}$ persülfat dozu optimum koşullarında Reactive Yellow 145 giderim verimi \%76,19 olarak belirlenmiştir.

-Oksidasyonu etkileyen en önemli parametre $\mathrm{pH}$ olup, giderim verimine katkısı \%80,06 seviyelerindedir. 
- Spektral taramada oksidasyon süresince Reactive Yellow 145 yapısındaki azo bağlarının kırıldığı, farklı aromatik bileşiklerin oluştuğu tahmin edilmektedir.

-Bu çalışmada elde edilen verilerden, doğada bol miktarda bulunan, endüstride yan ürün olarak oluşan alüminyum metalinin ileri oksidasyon prosesinde aktivatör olarak kullanılabileceği ispatlanmıştır. ZVAl kullanımı, persülfatın aktivasyonunda kullanılan 1sı1, UV 1şıma veya Fe ilavesi gibi metotlara bir alternatif olarak önerilmektedir.

\section{Teșekkür}

Bu çalışma Kocaeli Üniversitesi, BAP birimi tarafından FYL-2021-2621 nolu projesi ile desteklenmiştir. Yazarlar destek için teşekkür etmektedirler.

\section{Yazarların Katkıları}

NG çalışmanın orjinal ilk fikirini ortaya koyan kişi olup çalışmanın genel yürütücüsüdür. ŞD deneyleri gerçekleştirmiştir ve ED istatistiksel çözümlemeleri gerçekleştirmiştir. Makalenin yazımı ED ve NG tarafından ortak olarak gerçekleştirilmiştir.

\section{Çıkar Çatışması Beyanı}

Yazarlar arasında herhangi bir çıkar çatışması bulunmamaktadır.

\section{Araştırma ve Yayın Etiği Beyanı}

Yapılan çalışmada araştırma ve yayın etiğine uyulmuştur.

\section{Kaynaklar}

Arıcı, E., ve Keleştemur, O., (2018). Tufal katkılı harçların basınç dayanımının taguchi metodu ile analizi. Fırat üniversitesi mühendislik bilimleri dergisi, 30(3), 145-151.

Ajith, M. P., Aswathi, M., Priyadarshini, E., ve Rajamani, P. (2021). Recent innovations of nanotechnology in water treatment: A comprehensive review. Bioresource Technology, 342, 126000.

Bokare, A. D., ve Choi, W., (2009). Zero-valent aluminum for oxidative degradation of aqueous organic pollutants. Environmental Science and Technology, 43(18), 7130-7135.

Chkirida, S., Zari, N., Bouhfid, R., ve Qaiss, A. el kacem. (2021). Insight into the bionanocomposite applications on wastewater decontamination: Review. Journal of Water Process Engineering, 43, 102198.

Dhawane, S. H., Kumar, T., ve Halder, G., (2016). Biodiesel synthesis from Hevea brasiliensis oil employing carbon supported heterogeneous catalyst: Optimization by Taguchi method. Renewable Energy, 89, $506-514$. 
Dogan, M., Ozturk, T., Olmez-Hanci, T., ve Arslan-Alaton, I., (2016). Persulfate and hydrogen peroxideactivated degradation of bisphenol a with nano-scale zero-valent iron and aluminum. Journal of Advanced Oxidation Technologies, 19(2), 266-275.

Erdinç, A., ve Keleştemur, O. (2018). Tufal Katkılı Harçların Basınç Dayanımının Taguchi Metodu ile Analizi. Firat üniversitesi mühendislik bilimleri dergisi, 30(3), 145-151.

Gai, W. Z., Liu, W. H., Deng, Z. Y., ve Zhou, J. G. (2012). Reaction of Al powder with water for hydrogen generation under ambient condition. International Journal of Hydrogen Energy, 37(17), 13132-13140.

Gupta, G. K., ve Mondal, M. K. (2019). Bio-energy generation from sagwan sawdust via pyrolysis: Product distributions, characterizations and optimization using response surface methodology. Energy, 170, 423-437.

Jiang, Y., Yang, S., Liu, J., Ren, T., Zhang, Y., ve Sun, X., (2020). Degradation of hexabromocyclododecane (HBCD) by nanoscale zero-valent aluminum (nZVAl). Chemosphere, 244, 125536.

Kavc1, E., Üniversitesi, K., Mimarlık Fakültesi, M., Mühendisliği Bölümü, K., ve Özet, T. (2021). Direct Red BWS tekstil boyas1 adsorpsiyonunun Taguchi L9 $\left(3^{4}\right)$ ortogonal deney tasarımı ile araştırılması Investigations of adsorption of Direct Red BWS textile dye using Taguchi L9(3 4 ) orthogonal experimental design. Niğde Ömer Halisdemir Üniversitesi Mühendislik Bilimleri Dergisi, 10(1), 358363.

Khatri, J., Nidheesh, P. V., Anantha Singh, T. S., ve Suresh Kumar, M., (2018). Advanced oxidation processes based on zero-valent aluminium for treating textile wastewater. Chemical Engineering Journal, 348, $67-73$.

Li, Y., Zhang, Y., Yang, S., Xue, Y., Liu, J., Wang, M., Liu, S., ve Chen, Y., (2021). Citrate ligand-enhanced microscale zero-valent aluminum corrosion for carbon tetrachloride degradation with high electron utilization efficiency. Science of the Total Environment, 783, 146999.

Lin, K. Y. A., ve Lin, C. H. (2016). Simultaneous reductive and adsorptive removal of bromate from water using acid-washed zero-valent aluminum (ZVAl). Chemical Engineering Journal, 297, 19-25.

Lin, K. Y. A., Lin, C. H., ve Yang, H. (2017). Enhanced bromate reduction using zero-valent aluminum mediated by oxalic acid. Journal of Environmental Chemical Engineering, 5(5), 5085-5090.

Mahmoud, A. S., Farag, R. S., Elshfai, M. M., Mohamed, L. A., \& Ragheb, S. M., (2019). Nano Zero-Valent Aluminum (nZVAl) Preparation, Characterization, and Application for the Removal of Soluble Organic Matter with Artificial Intelligence, Isotherm Study, and Kinetic Analysis. Air, Soil and Water Research, 12, 1178622119878707.

Nidheesh, P. V., Khatri, J., Anantha Singh, T. S., Gandhimathi, R., ve Ramesh, S. T., (2018). Review of zerovalent aluminium based water and wastewater treatment methods. Chemosphere, 200, 621-631.

Rathi, B. S., Kumar, P. S., ve Vo, D. V. N. (2021). Critical review on hazardous pollutants in water environment: Occurrence, monitoring, fate, removal technologies and risk assessment. Science of The Total Environment, 797, 149134.

Ren, T., Yang, S., Jiang, Y., Sun, X., \& Zhang, Y. (2018). Enhancing surface corrosion of zero-valent aluminum (ZVAl) and electron transfer process for the degradation of trichloroethylene with the presence of persulfate. Chemical Engineering Journal, 348, 350-360.

Ren, T., Yang, S., Wu, S., Wang, M., ve Xue, Y., (2019). High-energy ball milling enhancing the reactivity of microscale zero-valent aluminum toward the activation of persulfate and the degradation of trichloroethylene. Chemical Engineering Journal, 374, 100-111.

Ren, T., Zhang, Y., Liu, J., Zhang, Y., ve Yang, S., (2020). Ethanol-assisted mechanical activation of zerovalent aluminum for fast and highly efficient removal of Cr(VI). Applied Surface Science, 533, 147543.

Ross PJ. (1996). Taguchi Techniques for Quality Engineering. Singapore: McGraw Hill Professional Editions, New York, United States.

Shen, W., Kang, H., ve Ai, Z., (2018). Comparison of aerobic atrazine degradation with zero valent aluminum and zero valent iron. Journal of Hazardous Materials, 357, 408-414.

Sohrabi, M. R., Khavaran, A., Shariati, S., ve Shariati, S., (2017). Removal of Carmoisine edible dye by Fenton and photo Fenton processes using Taguchi orthogonal array design. Arabian Journal of Chemistry, 10, S3523-S3531.

Sridevi, M., Nirmala, C., Jawahar, N., Arthi, G., Vallinayagam, S., ve Sharma, V. K. (2021). Role of nanomaterial's as adsorbent for heterogeneous reaction in waste water treatment. Journal of Molecular Structure, 1241, 130596.

Xie, S., Yang, Y., Gai, W. Z., ve Deng, Z. Y., (2020). Oxide modified aluminum for removal of methyl orange and methyl blue in aqueous solution. RSC Advances, 11(2), 867-875. 
Yang, S., Zheng, D., Ren, T., Zhang, Y., ve Xin, J., (2017). Zero-valent aluminum for reductive removal of aqueous pollutants over a wide $\mathrm{pH}$ range: Performance and mechanism especially at near-neutral $\mathrm{pH}$. Water Research, 123, 704-714.

Zhang, H., Cao, B., Liu, W., Lin, K., ve Feng, J., (2012). Oxidative removal of acetaminophen using zero valent aluminum-acid system: Efficacy, influencing factors, and reaction mechanism. Journal of Environmental Sciences, 24(2), 314-319. 